Biblioteca Universitaria

ISSN: 0187-750X

public@dgb.unam.mx

Universidad Nacional Autónoma de México

México

Cervantes Tovar, Isabel

Diccionario de constructores y artistas de bienes inmuebles nacionales

Biblioteca Universitaria, vol. 16, núm. 2, julio-diciembre, 2013, pp. 145-153

Universidad Nacional Autónoma de México

Distrito Federal, México

Disponible en: http://www.redalyc.org/articulo.oa?id=28529572005

- Cómo citar el artículo

- Número completo

- Más información del artículo

Página de la revista en redalyc.org

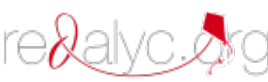

Sistema de Información Científica

Red de Revistas Científicas de América Latina, el Caribe, España y Portugal

Proyecto académico sin fines de lucro, desarrollado bajo la iniciativa de acceso abierto 


\section{Diccionario de constructores y artistas de bienes inmuebles nacionales}

\section{Dictionary of builders and artists of national real estate}

Isabel Cervantes Tovar*

\section{RESUImen}

El Diccionario de constructores y artistas de bienes inmuebles nacionales es el proyecto bibliográfico para el estudio de estos profesionistas del patrimonio edificado en México. Este producto es resultado del trabajo desarrollado en el Instituto de Investigaciones Bibliográficas de la UNAM, dentro de otro denominado Bibliografía del Patrimonio Histórico, Arquitectónico y Urbano Nacional y el acervo de la Biblioteca Nacional es su fuente de información.

La importancia de la sistematización de información sobre artistas y constructores radica en la novedosa posibilidad de consignar la información asentada en las fuentes a fin de relacionarla entre sí en un catálogo digitalizado. Esta herramienta ofrece al usuario accesibilidad, rapidez e información de calidad; además de ser una herramienta para estudiantes y un invaluable apoyo para investigadores y especialistas, así como un valioso instrumento de interés para el público en general.

Palabras clave: bibliografía, fuentes, arquitectos, alarifes, constructores, artistas, patrimonio, edificaciones.

\section{Abstract}

The Dictionary of Builders and Artists of National Real Estate is a bibliographic project to study these professionals of the built heritage in Mexico. This product is the result of the work developed in the Institute of Bibliographical Research of UNAM, within another called "Bibliography of Historical, Architectural and Urban National Heritage"; the collection of the National Library is its source of information.

The importance of the systematization of information on artists and builders lies in the novel possibility to enter the information established in the sources and interrelate it in a digital catalog. This tool offers the user accessibility, timeliness and information of quality, besides being a tool for students and an invaluable support for researchers and specialists, as well as a valuable instrument of interest to the general public.

KEYWORDS: Bibliography, sources, architects, builders, developers, artists, heritage, buildings.

Facultad de Filosofía y Letras (FFyL). Universidad Nacional Autónoma de México (UNAM). Circuito Interior, Ciudad Universitaria, 04510, México, D.F., México. Correo electrónico: isacer19@hotmail.com 


\section{Introducción}

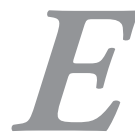

I patrimonio edificado es uno de los bienes capitales que retrata de mejor manera a la sociedad; su permanencia y valoración lo llevan a generar identidad. Él, por sí mismo, es el referente que habla de la sociedad que lo produce; por tal motivo, es de suma importancia todo instrumento que lo estudie o lo registre. Gran parte del capital constructivo de nuestro país ha desaparecido, por ello los instrumentos que lo consignan y que lo difunden fomentan y apoyan su permanencia.

En la Biblioteca Nacional se encuentra concentrado un acervo documental de invaluable riqueza sobre las obras edificadas en nuestro país. No sólo lo integran las publicaciones que en su momento fueron parte de las bibliotecas conventuales y sus colegios, de igual manera entre sus riquezas existen ediciones de los años cercanos a la creación de la imprenta en algunos países europeos. Así como se encuentran publicaciones antiguas, también encontramos las obras que han visto la luz en fechas recientes. Este acervo documental da cuenta de los diferentes periodos de nuestra historia tanto por sus editores como por la factura de las obras, por sus autores y por los temas que se abordan.

En la riqueza del patrimonio bibliográfico es posible rastrear la información de otro patrimonio nacional, el edificado. La necesidad de reconocer en cada edificación sus materiales, espacios, comitentes y constructores -entre otros muchos aspectos-genera múltiples cuestionamientos. Por ello, la amalgama obra-constructor ha generado a través del tiempo publicaciones monográficas, catálogos y estudios especializados. Sin lugar a dudas, una de las principales herramientas en cualquier investigación son los acervos bibliográficos, de tal suerte que su consulta responde y devela caminos para el estudio de la materia propuesta. Una parte importante de los textos que se encuentran en la Biblioteca Nacional son aquellos especializados en materia de edificaciones, constructores y artistas relacionados con este quehacer; ellos son el capital cultural y la memoria del patrimonio erigido.
No obstante, es necearia una herramienta que conjugue y consigne a través de nuevas tecnologías la información sobre el patrimonio edificado y sus constructores. Es así que en el proyecto denominado Bibliografía del Patrimonio Histórico, Arquitectónico y Urbano Nacional, desarrollado en el Instituto de Investigaciones Bibliográficas de la UNAM, uno de los ejes de trabajo, apoyado en las fuentes documentales de la Biblioteca Nacional, está encaminado a lograr el estudio de los constructores y artistas del patrimonio edificado en México.

Para efecto de este proyecto, el conjunto de textos seleccionados comprende las publicaciones que vieron la luz desde el último cuarto del siglo XIX y todo el siglo XX. Este conjunto se ha privilegiado porque en ellas se ha identificado rica información sobre los artistas que diseñaron y elevaron el patrimonio histórico de nuestro país.

Así, se implementó una labor multidisciplinaria en la que colaboraron bibliotecólogos, historiadores, arquitectos y técnicos en informática. Después de tres años de trabajo se reunió información sobre los artistas mexicanos y extranjeros que tuvieron actividad profesional en nuestro país entre los siglos $\mathrm{XVI}$ y $\mathrm{XX}$, en un producto al que se denominó Diccionario de constructores y artistas de bienes inmuebles nacionales.

\section{EI Diccionario}

El Diccionario es una valiosa herramienta que permitirá su consulta a todo usuario de la Biblioteca Nacional. El acceso a este producto será a través del portal de la Biblioteca, en donde la página web mostrará un recuadro titulado: Diccionario de constructores y artistas de bienes inmuebles nacionales. Pulsando este ícono el interesado accederá a la carátula, en la que tendrá a su disposición diferentes formas de consulta.

Las diversas opciones que el menú ofrece parten de ingresar alguno de los datos referentes a la obra, como: nombre del artista o edificador, seudónimo o simplemente apellido; otra forma de encontrar información es a partir del tipo de obra realizada, como catedral, convento o palacio. De igual manera, el despliegue res- 
ponde -por ejemplo- a nombres específicos como: Palacio de Bellas Artes, Hospicio Cabañas o Casa de Montejo. Así mismo, las diferentes búsquedas revelan información sobre las publicaciones que abordan las obras consignadas, es decir, por título o autor.

Este Diccionario será de utilidad para investigadores, estudiantes de diferentes niveles educativos y público en general, ya que aporta información biográfica relacionada con la actividad profesional de los múltiples autores de nuestro patrimonio. Cabe agregar que la riqueza de estos datos otorga diversas posibilidades de búsqueda a los interesados en torno a artistas, profesiones, fuentes y obras.

A pesar de que existen diccionarios y repertorios de artistas, el producto que aquí se presenta ofrecerá accesibilidad al permitir la consulta vía Internet, y en el caso de que el usuario necesite revisar la publicación original sabrá con certeza que la fuente forma parte del acervo de la Biblioteca Nacional. En este sentido, la importancia de la sistematización de información sobre artistas y constructores radica en la posibilidad de consignar los datos asentados en las fuentes, a fin de relacionarlos entre sí en un catálogo digitalizado. Así, en el momento en que el usuario realice una consulta podrá visualizar la información asentada por diferentes publicaciones sobre un creador o una obra determinada.

Otra de las bondades de este acervo es la rapidez y no sólo en la visualización de la información en la red. La información que el usuario obtiene detalla las fuentes y las páginas en las que hay noticias sobre el artista consultado. El universo de personajes que este producto consigna es de alrededor de mil registros, entre artistas y constructores.

No está de más mencionar que la cantidad de datos que el interesado obtiene es de calidad, porque en el Diccionario encontrará información como el momento y lugar de creación de la obra, las publicaciones que la mencionan y en algunos casos las imágenes.
Además, la información sobre los artistas se encuentra enriquecida con sus datos biográficos como lugar y fecha de nacimiento, así como de muerte; de igual manera hay periodos de actividad profesional en nuestro país tanto para artistas nacionales como extranjeros. Igualmente, se encuentran registradas las diferentes actividades artísticas y profesionales, así como otras obras realizadas por el mismo artista.

\section{La información en el Diccionario}

Como se ha mencionado, con la intención de formar un producto especializado en la temática que nos ocupa, el Diccionario contiene los artistas mexicanos y extranjeros que han tenido actividad profesional en nuestro país; sus nombres se registran según las diversas formas en que los autores los han asentado. Por tal motivo, hemos registrado bajo el rubro de Nombre Histórico el nombre completo u oficial, en el cual se incluye el nombre o nombres de pila y los apellidos. Ahora bien, bajo la etiqueta de Nombre de Fuente o Seudónimo se han colocado las diferentes formas escritas del nombre (véase fig. 1).

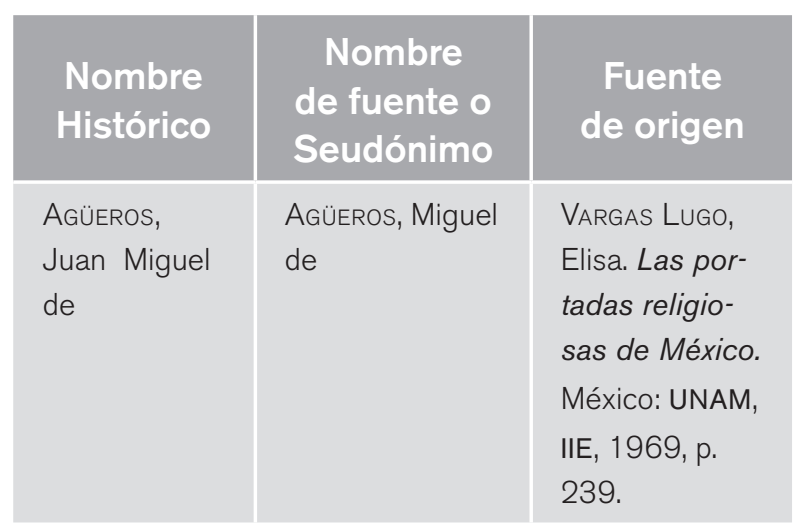

Fig. 1. Artista registrado con diferencias en el nombre.

Las diversas formas ortográficas con las que fueron referidos los nombres por el autor de la fuente de origen también quedaron registradas. La fuente de origen es la publicación que contiene información sobre el constructor y su obra, de la cual se genera la inclusión del edificador y su trabajo en el Diccionario (véase fig. 2). 


\begin{tabular}{|c|c|c|}
\hline $\begin{array}{l}\text { Nombre } \\
\text { Histórico }\end{array}$ & $\begin{array}{c}\text { Nombre } \\
\text { de fuente o } \\
\text { Seudónimo }\end{array}$ & $\begin{array}{c}\text { Fuente } \\
\text { de origen }\end{array}$ \\
\hline $\begin{array}{l}\text { BARROSO DE } \\
\text { LA ESCAYOLA, } \\
\text { Vicente. } \\
\text { (Italia ca. } \\
\text { 1609- México } \\
\text { 1692) }\end{array}$ & $\begin{array}{l}\text { BARROSO DE LA } \\
\text { ESCAYOLA, Vicencio } \\
\text { (Nombre según la } \\
\text { publicación) } \\
\text { ESCAIOLA, Vicencio } \\
\text { BAROCIO DE VIÑOLA Y } \\
\text { ESCAYOLA, Vicencio. } \\
\text { BARROCIO DE ESCAYU- } \\
\text { LA, Bisencio }\end{array}$ & $\begin{array}{l}\text { Mazín, Oscar, } \\
\text { Elena I. Estrada } \\
\text { DE Gerlero, Herón } \\
\text { PÉREZ MARTínEZ, et } \\
\text { al. La Catedral de } \\
\text { Morelia. Zamora: } \\
\text { El Colegio de } \\
\text { Michoacán : Gobi- } \\
\text { erno del Estado de } \\
\text { Michoacán, 1991, } \\
\text { pp. 9, 32, 34-37, } \\
\text { 45- 47. }\end{array}$ \\
\hline
\end{tabular}

Fig. 2. Artista registrado de diferentes formas.

Otro derivado en el nombre es el de "Nombre de Fuente o Seudónimo," que se genera del registro del nombre más conocido, del seudónimo, e incluso de su firma (véase fig. 3). Algunos artistas han sido conocidos o identificados a través de su firma, ya sea estampada en contratos o en sus obras.

\begin{tabular}{|c|c|c|}
\hline $\begin{array}{l}\text { Nombre } \\
\text { Histórico }\end{array}$ & $\begin{array}{c}\text { Nombre } \\
\text { de fuente o } \\
\text { Seudónimo }\end{array}$ & $\begin{array}{c}\text { Fuente } \\
\text { de origen }\end{array}$ \\
\hline $\begin{array}{l}\text { MALDONADO Y } \\
\text { CABRERA, Miguel } \\
\text { Mateo } \\
\text { (México 1695- } \\
1768 \text { ) }\end{array}$ & CABrera, Miguel & $\begin{array}{l}\text { MAZA, Francisco } \\
\text { de la. El palacio de } \\
\text { la Inquisición: Es- } \\
\text { cuela Nacional de } \\
\text { Medicina. México: } \\
\text { UNAM, Instituto de } \\
\text { Investigaciones } \\
\text { Estéticas, 1951, } \\
\text { p. } 62 .\end{array}$ \\
\hline
\end{tabular}

Fig. 3. Registro del artista por su nombre más conocido.

De igual manera, forman parte de nuestro producto aun los mencionados solamente por su nombre de pila, como por ejemplo el alarife Cornelio, que edificó una casa en Querétaro.

Además, esta herramienta consigna en la mayoría de los casos el lugar de nacimiento y muerte de los artistas y constructores, así como sus fechas extremas. Tal información se recabó inicialmente de la publicación que da origen al registro, pero en ocasiones hemos recurrido al apoyo de fuentes especializadas como el Repertorio de artistas de México de Guillermo Tovar y de Teresa, La escuadra y el cincel de Mina Ramírez Montes, Arquitectura del s. xIx de Israel Katzman, Arte colonial en México de Manuel Toussaint, Arquitectura religiosa de George Kubler y Artistas y artesanos de Glorinela González Franco, entre otras.

Todas estas publicaciones forman parte de la colección de fuentes secundarias consignadas en la base. También conviene mencionar que se señalan las páginas en las que se ubican estos datos (véase fig. 4).

\begin{tabular}{|c|c|c|}
\hline $\begin{array}{l}\text { Nombre } \\
\text { Histórico }\end{array}$ & $\begin{array}{c}\text { Fuente de } \\
\text { origen }\end{array}$ & $\begin{array}{c}\text { Fuentes } \\
\text { secundarias }\end{array}$ \\
\hline $\begin{array}{l}\text { XIMENO Y PLA- } \\
\text { NÉS, Rafael } \\
\text { (España ca. } \\
1759 \text { - México } \\
\text { 1825) }\end{array}$ & $\begin{array}{l}\text { FERNÁNDEZ, Martha. } \\
\text { Ciudad rota: la } \\
\text { Ciudad de México } \\
\text { después del sis- } \\
\text { mo. México: UNAM, } \\
\text { IE, 1990, p. } 182 \text {. }\end{array}$ & $\begin{array}{l}\text { TOVAR DE TERESA, } \\
\text { Guillermo. Reper- } \\
\text { torio de artistas en } \\
\text { México. México: } \\
\text { Grupo Financiero } \\
\text { Bancomer, } 1995 \text {. } \\
\text { T. 3, p. } 414 \text {. }\end{array}$ \\
\hline
\end{tabular}

Fig. 4. Registro de lugar de nacimiento y muerte, así como fechas extremas.

Un aporte novedoso que ofrece el Diccionario es el referente al periodo de actividad profesional que el artista tuvo en México, trátese de los mexicanos o de aquellos extranjeros que trabajaron en nuestro país sólo una temporada, o quienes llegaron y residieron en nuestro territorio hasta el final de sus días (véase fig. 5). Esta información se encuentra en el recuadro de "Nombre Histórico" y se destaca en cursivas como en el siguiente ejemplo:

\begin{tabular}{|c|c|c|}
\hline $\begin{array}{l}\text { Nombre } \\
\text { Histórico }\end{array}$ & $\begin{array}{c}\text { Nombre } \\
\text { de fuente o } \\
\text { Seudónimo }\end{array}$ & $\begin{array}{l}\text { Fuente } \\
\text { de origen }\end{array}$ \\
\hline $\begin{array}{l}\text { Roısın, Maxime } \\
\text { (Francia, ¿-¿) } \\
\text { 1897-1914 }\end{array}$ & $\begin{array}{l}\text { Altares de la } \\
\text { patria. México: } \\
\text { Departamento } \\
\text { del Distrito Fe- } \\
\text { deral, Dirección } \\
\text { General de } \\
\text { Acción Social, } \\
\text { 1956, p. } 20 .\end{array}$ & $\begin{array}{l}\text { KATZMAN, Ismael. } \\
\text { Arquitectura } \\
\text { del siglo xix en } \\
\text { México. México: } \\
\text { Trillas, 1993, p. } \\
376 .\end{array}$ \\
\hline
\end{tabular}

Fig. 5. Registro de periodo de actividad profesional de un artista extranjero en México. 
Además, el Diccionario proporciona en primer lugar los datos sobre la profesión o la actividad artística que se consigna en la publicación de origen. Conjuntamente, esta información se enriquece ya que en segundo orden inscribimos otras profesiones o actividades recabadas en esa misma fuente o en otras que abordan al mismo artista. Ejemplo de ello es el del arquitecto, escultor y profesor de arquitectura Manuel Tolsá (véase fig. 6).

\begin{tabular}{|c|c|c|c|c|}
\hline $\begin{array}{l}\text { Nombre } \\
\text { histórico }\end{array}$ & $\begin{array}{c}\text { Profesión } \\
\text { principal } \\
\text { asentada por la } \\
\text { fuente }\end{array}$ & $\begin{array}{c}\text { Otras profesiones o } \\
\text { Actividades }\end{array}$ & $\begin{array}{l}\text { Fuente } \\
\text { De origen }\end{array}$ & $\begin{array}{c}\text { Fuentes } \\
\text { Secundarias }\end{array}$ \\
\hline $\begin{array}{l}\text { Tolsá, Manuel } \\
\text { (España, 1757 - } \\
\text { México 1816) } \\
1791 \text { - } 1813\end{array}$ & $\begin{array}{l}\text { Arquitecto } \\
\text { (activo en México } \\
\text { entre el último } \\
\text { cuarto del s. XVIII y } \\
\text { primero del s. XIX) }\end{array}$ & $\begin{array}{l}\text { Escultor, } \\
\text { Maestro Mayor de la Cate- } \\
\text { dral de México, } \\
\text { Director de escultura de la } \\
\text { Academia de San Carlos. }\end{array}$ & $\begin{array}{l}\text { BARGelLinI, Clara [et } \\
\text { al.]. Casas señoriales } \\
\text { del Banco Nacional } \\
\text { de México. México: } \\
\text { Fomento Cultural Ba- } \\
\text { namex, 1999, p. } 44 .\end{array}$ & $\begin{array}{l}\text { TOVAR DE TERESA, } \\
\text { Guillermo. Repertorio } \\
\text { de artistas en México: } \\
\text { artes plásticas y } \\
\text { decorativas. México: } \\
\text { Fundación Cultural } \\
\text { Bancomer, t. 3, 1995, } \\
\text { p. } 334 \text {. }\end{array}$ \\
\hline
\end{tabular}

Fig. 6. Registro con varias actividades profesionales.

Al respecto, dentro de este apartado tenemos casos particulares y sorprendentes, como son los de los frailes consignados por diferentes autores, constructores de alguna iglesia o conjunto conventual, que sin ostentar el título de arquitectos durante el siglo XVI fueron los más importantes edificadores en la Nueva España. Por ello, dentro de su actividad profesional principal los hemos registrado como constructores, respondiendo al primer objetivo de este producto, mientras que en el apartado denominado "otra profesión o actividad" han sido registrados como frailes (véase fig. 7).

\begin{tabular}{|c|c|c|c|c|}
\hline $\begin{array}{l}\text { Nombre } \\
\text { histórico }\end{array}$ & $\begin{array}{c}\text { Profesión } \\
\text { principal } \\
\text { asentada por la } \\
\text { fuente }\end{array}$ & $\begin{array}{c}\text { Otras profesiones o } \\
\text { Actividades }\end{array}$ & $\begin{array}{l}\text { Fuente } \\
\text { De origen }\end{array}$ & $\begin{array}{c}\text { Fuentes } \\
\text { Secundarias }\end{array}$ \\
\hline $\begin{array}{l}\text { AlamedA, Juan } \\
\text { de, fray } \\
\text { (España ¿? - } \\
\text { México 1570) } \\
1529 \text { - } 1568\end{array}$ & Constructor. & Fraile & $\begin{array}{l}\text { MCANDREW, John. The } \\
\text { open-air churches of } \\
\text { sixteeth-century Mexi- } \\
\text { co. Cambridge, Mass: } \\
\text { Harvard University } \\
\text { Press, 1965, pp. 127, } \\
244,334 \text { - 339, } 444 .\end{array}$ & $\begin{array}{l}\text { KUBLER, George. Ar- } \\
\text { quitectura mexicana } \\
\text { del siglo xvı. Tercera } \\
\text { reimp. México: Fondo } \\
\text { de Cultura Económi- } \\
\text { ca, 1992, p. } 121 .\end{array}$ \\
\hline
\end{tabular}

Fig. 7 Registro de actividad profesional, el caso de religiosos.

Otros casos interesantes relacionados con la actividad profesional son los de los artistas que fueron asentados como 'alarifes', arquitectos y 'maestros de albañilería', pues esta designación fue utilizada indistintamente a lo largo del periodo colonial para nombrar a los "maestros examinados." 
Es necesario tener presente que durante dicha época estas profesiones se organizaban dentro de gremios. El aprendizaje, los exámenes para obtener un lugar dentro del gremio y la posterior actividad correspondiente estaban regulados por esta asociación; por ello, entre los artistas identificados encontramos aprendices, ayudantes, oficiales, maestros y 'veedores de arquitectura'. Estos últimos estaban designados con el mayor cargo dentro de una organización jerarquizada que englobaba experiencia, prestigio social y reconocimiento de parte del gremio y de las autoridades gubernamentales.

Otros profesionistas de gran relevancia dentro de la actividad constructiva eran los ingenieros. La ingeniería es una profesión de origen militar que desarrolló sus habilidades y conocimientos especialmente en la construcción de caminos, puentes y fortalezas. Por su origen, aquéllos no estaban constituidos en algún gremio y a lo largo del tiempo incursionaron en diversos trabajos relacionados con el mundo de la construcción y el urbanismo (véase fig. 8).

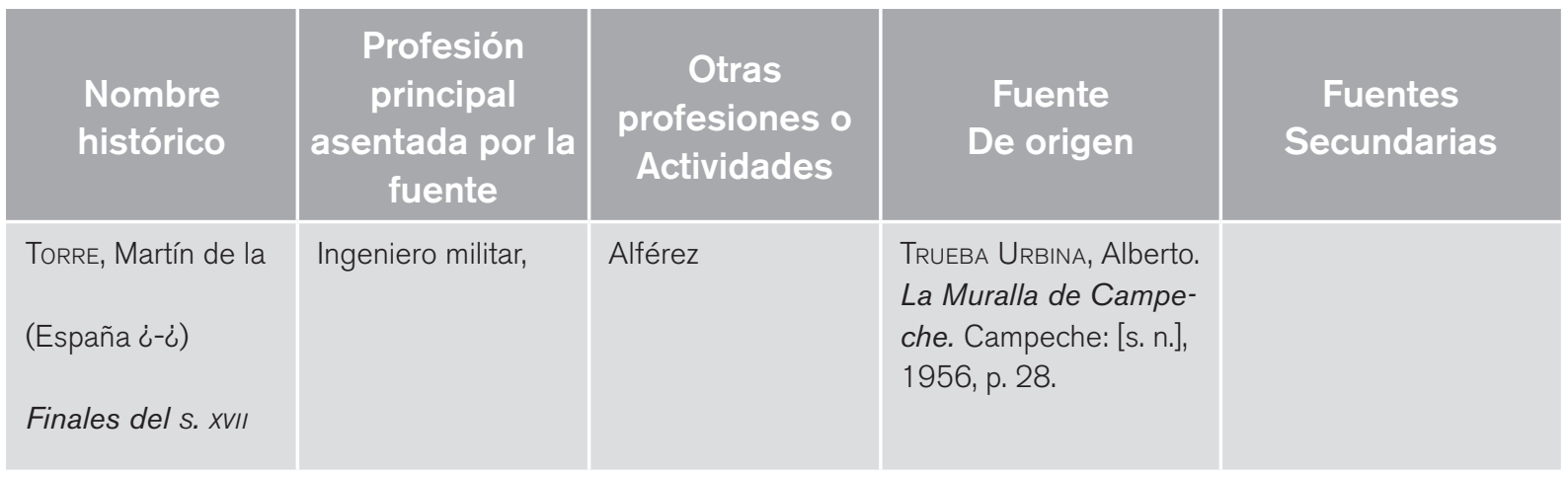

Fig. 8. Registro de actividad profesional, el caso de los ingenieros.

Incluso, no faltaron quienes realizaron actividades complementarias o indirectas en las edificaciones y en la traza de ciudades, como el 'agrimensor' que media la tierra. Estos hombres que participaron activamente en la traza de ciudades son denominados en algunas fuentes como 'geómetras'. A su vez, los carpinteros, constituidos de igual forma en gremios, se diversificaron independientemente de su escala jerárquica. Había entre ellos especialistas de acuerdo con el tipo de labor que realizaban, por ejemplo los 'ensambladores', los 'carpinteros de lo blanco' y los 'carpinteros de lo negro' (véase fig. 9).

\begin{tabular}{|c|c|c|c|c|}
\hline $\begin{array}{l}\text { Nombre } \\
\text { histórico }\end{array}$ & $\begin{array}{c}\text { Profesión } \\
\text { principal } \\
\text { asentada por la } \\
\text { fuente }\end{array}$ & $\begin{array}{c}\text { Otras } \\
\text { profesiones } \\
\text { Actividades }\end{array}$ & $\begin{array}{l}\text { Fuente } \\
\text { De origen }\end{array}$ & $\begin{array}{c}\text { Fuentes } \\
\text { Secundarias }\end{array}$ \\
\hline $\begin{array}{l}\text { GuedEA, Anastasio } \\
\text { (México ¿? - ¿?) } \\
1734-1740\end{array}$ & Ensamblador & Retablista. & $\begin{array}{l}\text { Mazín, Oscar, Elena I. } \\
\text { EstradA DE GERLero, } \\
\text { Herón PÉrez MARTínez. } \\
\text { La catedral de Morelia. } \\
\text { Zamora: El Colegio de } \\
\text { Michoacán : Gobierno } \\
\text { del Estado de Michoa- } \\
\text { cán, 1991, pp. 55, } 149 .\end{array}$ & $\begin{array}{l}\text { Realizó la escultura } \\
\text { de un crucifijo para la } \\
\text { Sacristía de la catedral, } \\
\text { y a él se le atribuye el } \\
\text { retablo del Santo Cristo } \\
\text { ubicado en la Capilla de } \\
\text { fray Marcos. }\end{array}$ \\
\hline
\end{tabular}

Fig. 9. Registro de actividad profesional dentro del gremio de carpinteros, el caso de ensambladores. 
No debe olvidarse tampoco a los 'canteros', que eran los expertos que labraban la piedra, dando soluciones que determinaban el diseño ornamental de los elementos arquitectónicos. Por último, dentro de las labores ejecutadas por peritos en su materia es de interés mencionar a los 'doradores', ellos eran los artistas que cubrían de oro la superficie de alguna obra, detallando y dando punto final tanto a trabajos individuales y colectivos como esculturas, retablos, nichos y altares entre otros (véase fig. 10).

\begin{tabular}{|c|c|c|c|c|c|}
\hline $\begin{array}{l}\text { Nombre } \\
\text { histórico }\end{array}$ & $\begin{array}{l}\text { Nombre de } \\
\text { fuente o } \\
\text { seudónimo }\end{array}$ & $\begin{array}{c}\text { Profesión principal } \\
\text { asentada por la } \\
\text { fuente }\end{array}$ & $\begin{array}{c}\text { Fuente de } \\
\text { origen }\end{array}$ & $\begin{array}{c}\text { Fuentes } \\
\text { Secundarias }\end{array}$ & Obras \\
\hline $\begin{array}{l}\text { CentilLanA, } \\
\text { Francisco } \\
\text { (México ¿?- } \\
\text { ¿?) } \\
\text { ca. } 1625\end{array}$ & $\begin{array}{l}\text { CANTILLANA, Fran- } \\
\text { cisco }\end{array}$ & $\begin{array}{l}\text { Dorador } \\
\text { (activo en México hacia } \\
\text { el primer cuarto del S. } \\
\text { XVII) }\end{array}$ & $\begin{array}{l}\text { DenA, Gabriela, } \\
\text { BLANCo, Carlos. } \\
\text { Yuriria, Guanajua- } \\
\text { to: templo y ex- } \\
\text { convento. México : } \\
\text { CNCA : INAH, } 1993 .\end{array}$ & $\begin{array}{l}\text { KUBLER, George. } \\
\text { Arquitectura } \\
\text { mexicana del } \\
\text { Siglo XVI. México: } \\
\text { FCE, 1992. p. } 628 .\end{array}$ & $\begin{array}{l}\text { Dorador de los } \\
\text { retablos de la } \\
\text { iglesia del ex } \\
\text { convento de } \\
\text { Yuriria. }\end{array}$ \\
\hline
\end{tabular}

Fig. 10. Registro de actividad profesional dentro del gremio de carpinteros, el caso de doradores.

\section{Bibliografía complementaria}

Por otro lado, en el apartado de fuente de origen el usuario puede visualizar la ficha bibliográfica completa, indicándose en ella las páginas de las que se obtuvo la información consignada. Como ya se ha mencionado, una de las riquezas de este Diccionario radica en la disposición de localizar las diferentes fuentes en las que se aborda a cada uno de los artistas y constructores registrados, esta información es visible en el apartado denominado "fuentes secundarias". Para complementar la información sobre un artista, los registros de éste -que han sido generados por otras fuentes de origen- pueden relacionarse entre sí para incrementar el caudal de información sobre el profesional a consultar.

\section{Patrimonio artístico}

Otra de las características que ofrece el Diccionario es la posibilidad de incrementar la información en torno a las obras en las que participaron los artistas. Estos datos están inscritos a partir de la fuente que dio origen al registro, por ello se encuentran descritos como los consigna el autor (véase fig. 11). En algunos casos no sólo señala la obra artística realizada sino también se enriquece la búsqueda con datos como lugar de ubicación y el motivo de su factura; en otros casos se señala que el trabajo fue una obra realizada en conjunto con otros profesionales.

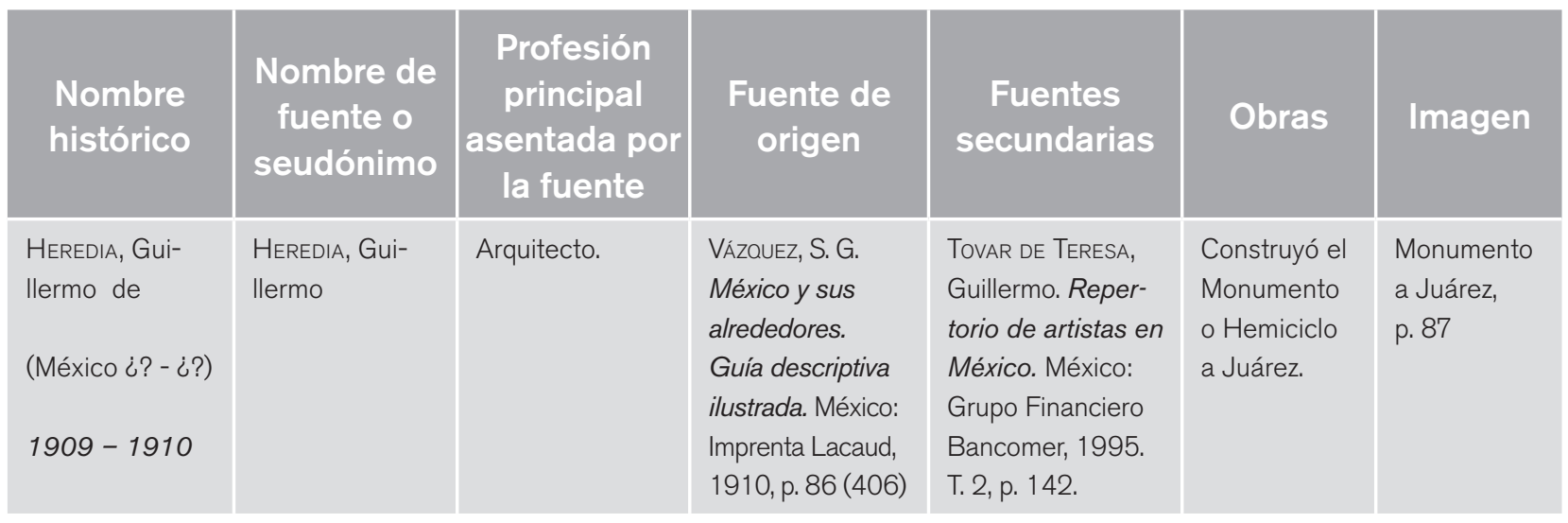

Fig. 11. Registro completo.

1 García Salinero, Fernando. Léxico de alarifes de los siglos de Oro. Madrid: Real Academia Española, 1968, p. 101. 
Así, tenemos registradas obras que se circunscriben en el periodo novohispano en modalidades como manierista, plateresco, salomónico, estípite, neóstilo y anástilo, entre otras; o bien obras representativas del neoclásico o el neocolonial, por mencionar algunos periodos.

Por si esto no fuera suficiente, hemos llevado a cabo la labor de reproducir y poner a disposición del usuario las imágenes de las obras que están disponibles; así, los interesados tendrán a la mano la información biográfica y profesional del autor, a la que le podrán sumar la visualización de algunas de sus creaciones.

Sobre esta base, se facilita el análisis de varias obras representativas de la arquitectura eclesiástica novohispana, como los conjuntos conventuales de Huejotzingo en Puebla, Acolman en el Estado de México o Yanhuitlán en Oaxaca; o de la arquitectura civil como la Aduana, el Palacio de Gobierno o el Palacio de los Condes de Valparaíso, todos ellos en la Ciudad de México. Además, de igual forma están disponibles las imágenes de obras pictóricas y monumentos realizados en México en diferentes momentos constructivos.

\section{Conclusiones}

Es deseable señalar que entre las múltiples riquezas del Diccionario destaca la integración de información tanto convencional como novedosa. La primera de ellas se basa en datos como nombre y fechas de nacimiento y muerte, antecedentes fundamentales en toda búsqueda. Sin embargo, los periodos de actividad profesional tanto para artistas mexicanos como extranjeros, la consignación de diversas publicaciones que abordan el asunto investigado y las imágenes que contienen las publicaciones son novedades en el campo de obras de consulta. Dentro de la nueva línea de información se encuentran las diversas actividades profesionales referidas en las fuentes consultadas. Esto nos lleva a conocer un poco más sobre actividades especializadas en el ramo de la construcción.

Es necesario resaltar que esta herramienta integra y concentra la información que diversas fuentes ofrecen sobre los artistas y constructores, así como de sus obras, otorgando riqueza en las referencias para toda consulta. Esta tarea nos ha permitido reconocer el valor de los datos tomados de las publicaciones; por tal motivo, es pertinente señalar que se ofrecen múltiples formas de exploración a través del Diccionario para la mejor ubicación de referencias.

Como instrumento de búsqueda en línea el Diccionario no sólo ofrece señalar la fuente, sino que entrega inmediatamente valiosos datos que responderán a necesidades primarias y básicas de quienes lo consulten, pues uno de sus objetivos es facilitar el camino de la investigación, agilizando las búsquedas y minimizando los tiempos. Con ello se le permite al especialista que concentre sus esfuerzos en el desarrollo de su investigación.

Por último, es necesario apuntar que este Diccionario no es un producto acabado, más bien es el inicio de un proyecto en crecimiento; un crecimiento que planeamos no sólo en el número de artistas consignados sino en las posibilidades académicas y tecnológicas que se ofrecen. cos

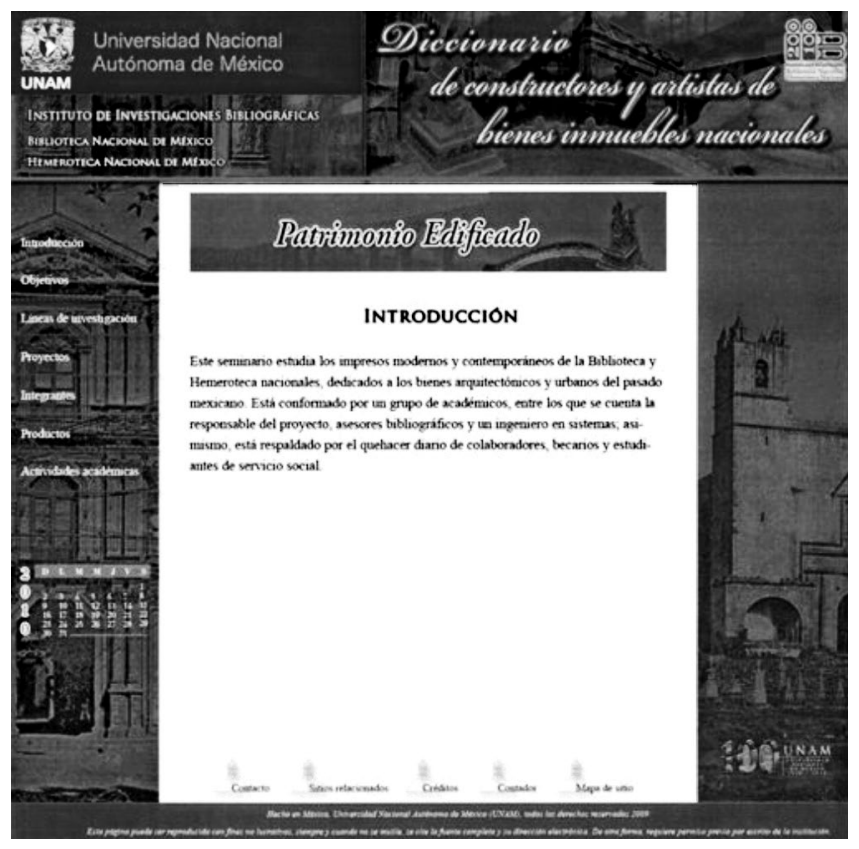

Fig. 12. Portal del Diccionario de constructores y artistas de bienes inmuebles nacionales. 


\section{Obras Consultadas}

Artistas y artesanos a través de fuentes documentales. Glorinela González Franco y otros. México: Instituto Nacional de Antropología e Historia, 1995. 2 v.

BÁez Macías, Eduardo. Historia de la Escuela Nacional de Bellas Artes: antigua Academia de San Carlos, 1781-1910. México: Escuela Nacional de Artes Plásticas, 2008. 309 p.

Guía del archivo de la antigua Academia de San Carlos: 1867-1910. México: unAm, Instituto de Investigaciones Estéticas, 2003. 581 p.

Catálogo de artistas y artesanos de México. Glorinela González Franco y otros. México: Instituto Nacional de Antropología e Historia, 1986. 293.

Fernández, Martha. Arquitectura y gobierno virreinal. Los maestros mayores de la Ciudad de México siglo XVII. México: UNAM, Imprenta Universitaria, 1985. 418 p.

La arquitectura de la ciudad de México en el siglo XVII. México: DDF, Secretaría General de Desarrollo Social, Comité Interno de Ediciones Gubernamentales, Ciudad y Cultura, 1987. 43 p.

García Salinero, Fernando. Léxico de alarifes de los siglos de oro. Madrid: Real Academia Española, 1968. 280 p.

Katzman, Israel. Arquitectura del siglo XIX en México. México: UnAm, Centro de Investigaciones Arquitectónicas, 1973. V.

Kubler, George. Arquitectura mexicana del siglo XVI. México: Fondo de Cultura Económica, 1983. 683 p.

Mariscal, Federico. La Patria y la arquitectura nacional. México: Impresora del Puente Quebrado, 1970. 119 p.

Ramírez Montes, Guillermina. La escuadra y el cincel: documentos sobre la construcción de la catedral de Morelia. México: UNAM, Instituto de Investigaciones Estéticas, 1987. 181 p.

Revilla, Manuel Gustavo Antonio. El arte en México, en la época antigua y durante el gobierno virreinal. México: Secretaría de Fomento, 1893. 110 p.

Toussaint, Manuel. Arte colonial en México. México: unam, Instituto de Investigaciones Estéticas, Imprenta Universitaria, 1962.

Tovar de Teresa, Guillermo. Repertorio de artistas en México: artes plásticas y decorativas. México: Fundación Cultural Bancomer, 1995. 3 v. 